Review

\title{
Nutrition, Cancer Genetics and Epigenetics
}

\author{
Kenneth Lundstrom *
}

PanTherapeutics, Rte de Lavux 49, Lutry, Switzerland; E-Mail: lundstromkenneth@gmail.com

* Correspondence: Kenneth Lundstrom; E-Mail: lundstromkenneth@gmail.com

Academic Editor: Lunawati Bennett

Special Issue: Cancer Genetics and Epigenetics Alterations

\section{OBM Genetics}

2019 , volume 3 , issue 4

doi:10.21926/obm.genet.1904099
Received: October 01, 2019

Accepted: November 20, 2019

Published: November 28, 2019

\begin{abstract}
Epidemiological data and meta-analysis have confirmed that there exists a strong association between nutrition and disease risk. In the context of cancer, it has been demonstrated that unhealthy diets increase the risk of disease. On the other hand, major dietary interventions and lifestyle changes have been demonstrated to provide therapeutic efficacy in cancer patients. Genetic mechanisms have been reported to be associated with cancer development induced by environmental and nutritional factors. Genetics plays an important role in the designing of personalized drugs and diets. Epigenetics has also been demonstrated to be affected by nutrition, leading to increased risk of disease when unhealthy diets are consumed, while healthy nutrition is able to provide both prophylactic and therapeutic efficacy.
\end{abstract}

\section{Keywords}

Nutrition; nutrigenomics; cancer; genetics; epigenetics; drugs

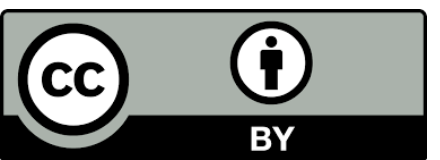

(C) 2019 by the author. This is an open access article distributed under the conditions of the Creative Commons by Attribution License, which permits unrestricted use, distribution, and reproduction in any medium or format, provided the original work is correctly cited. 


\section{Introduction}

Data from numerous epidemiological studies and meta-analyses have confirmed that nutrition serves as an important factor in relation to human health [1]. However, the knowledge of the impact of nutrition on human health has been hampered due to lack of critical scientific evaluation. In particular, the efficacy of traditional plant-based diets has relied mainly on social and ethnic verification. However, major technological progress in the fields of bioinformatics, genomics, and proteomics research has led to the development of novel methods for the evaluation of effects of nutrition on human health, and has also bridged the gap between traditional plant-based treatment of disease and modern science-based approaches to disease treatment [2]. In this context, thorough clinical evaluation of plant-based drugs has become popular. However, identifying the specific action of the individual components of such drugs is a difficult task because recording the patient's food intake has relied on information provided by the individuals in questionnaires; this has encouraged improved documentation of dietary intake through photography and designing of valid guidelines [3].

In regard to disease risk and therapeutic effect, nutrition plays an important role [4]. Numerous studies have demonstrated that the dietary intake of vegetables and fruits contributes to reducing disease risk [5]. Major dietary modifications and lifestyle changes have been reported to demonstrate therapeutic effect in patients with various diseases [6]. The present review focuses on cancer, describing the impact that nutrition can exert on the prevention and treatment of this disease. Furthermore, the relationship between cancer genetics and epigenetics is discussed.

\section{Nutrition and Cancer Risk}

In the context of cancer, it has been suggested that nutrition is responsible for the risk of onethird of the cancer cases in the US already in the 1980s [7]. Moreover, the World Cancer Research Fund and American Institute of Cancer Research have stated the essential role of nutrition in cancer development worldwide [8]. More recently, it has been indicated that two-thirds of the deaths caused by cancer could be prevented just by switching to a healthier diet and implementing lifestyle changes [9]. The molecular and genetic basis of cancer development are discussed later in the review, while the effects of various nutritional components on different cancers are summarized in Table 1. It has been reported that nutrition in the form of plant-based foods may exert a positive effect manifesting in the form of reduced risk of cancer [10], while a high intake of red meat and fat may enhance the risk [11]. Several meta-analyses have suggested both prophylactic and therapeutic benefits associated with various cancers by introducing dietary changes $[12,13]$. A systematic review and meta-analysis of 18 publications specifically indicated a positive association between red meat consumption and the increased risk of glioma [10]. In contrast, a diet containing fish which was rich in poly-unsaturated fatty acids (PUFAs) was reported to contribute to the reduced risk of brain cancer in a meta-analysis of nine observational studies [14]. In regard to colon cancer, an inverse relationship between a diet rich in vegetables and fruits and esophageal squamous cell carcinoma was established in the European Prospective Investigation of Cancer and Nutrition (EPIC) study [11]. Similarly, in a study conducted in Western Australia, the risks of developing proximal colon and rectal cancers were observed to have reduced upon the intake of Brassica vegetables [15]. In contrast, a systematic review and metaanalysis demonstrated the association of red meat and processed meat with the overall risk of 
colorectal cancer, and not rectal cancer [16]. However, according to the findings of a meta-analysis of cohort studies on gastric cancer, no association was discovered between red and processed meat consumption and cancer risk, while the case-control studies reported a positive association [17]. In regard to coffee intake, it was demonstrated that coffee, as opposed to decaffeinated drinks and caffeine, decreased the development of dysplastic crypts in rats exposed to $\mathrm{N}$-methyl$\mathrm{N}$-nitro-N-nitrosoguanidine (MNNG) [18]. Owing to either neutral or beneficial effects of coffee based on comprehensive epidemiological and experimental data, the association of coffee consumption with breast, prostate, colorectal, and liver cancers was evaluated [19], It was revealed that coffee provided protection against liver and colorectal cancers, while no association between the overall risk of breast and prostate cancers and coffee intake could be determined. It has been suggested that phytochemicals in coffee provide chemoprevention through inhibition of oxidative stress and oxidative damage, regulation of DNA repair, apoptosis, and inflammation. Moreover, anti-proliferative, anti-angiogenic, and anti-metastatic effects of coffee have been indicated. Another study revealed that coffee consumption was associated with a reduced risk of endometrial cancer [20]. However, in the EPIC study, a 14-year-long follow-up investigation demonstrated no association between coffee or tea consumption and the risk of thyroid cancer [21]. Moreover, the two main active ingredients of green tea, catechins and theanine, have been reported to be associated with a reduced risk of colon and esophageal cancers [22]. In another study, the anti-carcinogenic effect of the polyphenol named epigallocatechin gallate (EGCG) present in green tea was demonstrated to lead to a reduced risk of prostate cancer in Chinese men in Hong Kong [23]. Various spices, such as ginger, turmeric, black cumin, garlic, saffron, black pepper, and chili pepper, have also been reported to possibly provide prevention and treatment of colorectal and stomach cancers [24].

In regard to breast cancer, nutritional interventions have exhibited an impact on disease risk $[25,26]$. For instance, fiber intake was reported to provide a significant dose-response to reduced breast cancer risk. Moreover, soybean consumption has been associated with a reduced risk of breast cancer in Asian women [27], while fruit and vegetable intake during adolescence has been associated with a lower risk of breast cancer in premenopausal women in the US [28]. Similarly, another study described a reduced risk of breast cancer in women with a high intake of vitamin D [29]. In contrast, an increased risk of estrogen receptor-negative breast cancer was observed in women who were committed to a diet high in grains, dairy, and sugar and low in vegetables and fish [30]. A dose-response meta-analysis investigating the relationship between egg consumption and the risk of breast, prostate, and ovarian cancers revealed non-significant increase in breast cancer risk, although it was suggested that a positive association between egg intake and fatal prostate and ovarian cancers with an increase in egg consumption to five eggs per week could not be ruled out [31]. Furthermore, the association between dietary fiber intake and the risk of ovarian cancer was observed in a meta-analysis of 19 studies involving 567,742 participants [32]. Dose-response analysis indicated that for each $5 \mathrm{~g} /$ day increment in the dietary fiber intake, the risk of ovarian cancer decreased by $3 \%$. In another study conducted with African American women, it was indicated that adherence to an overall healthy dietary pattern including fiber may reduce the risk of ovarian cancer, especially among postmenopausal women [33]. Moreover, high sugar intake has been reported to be associated with an increased risk of ovarian cancer in African American women [34]. 
Table 1 Examples of nutrition association with various cancers.

\begin{tabular}{|c|c|c|c|}
\hline Cancer & Nutrient/Source & Effect & Ref \\
\hline Brain & $\begin{array}{l}\text { Red meat } \\
\text { PUFAs in fish }\end{array}$ & $\begin{array}{l}\text { Significantly reduced glioma risk in humans } \\
\text { Reduced brain tumor risk in humans }\end{array}$ & $\begin{array}{l}10] \\
{[14]}\end{array}$ \\
\hline Breast & $\begin{array}{l}\text { Fiber } \\
\text { Soybeans } \\
\text { Fruit and vegetable consumption } \\
\text { Vitamin D } \\
\text { Diet rich grains, dairy, and sugar } \\
\text { Flavonoids }\end{array}$ & $\begin{array}{l}\text { Significantly reduced breast cancer risk in humans } \\
\text { Significantly reduced breast cancer risk in Asians } \\
\text { Reduced premenopausal cancer risk in humans } \\
\text { Protection against breast cancer in humans } \\
\text { Increased risk of ER breast cancer in humans } \\
\text { Reduced breast cancer risk in humans }\end{array}$ & $\begin{array}{l}{[25,26]} \\
{[27]} \\
{[28]} \\
{[29]} \\
{[30]} \\
{[35]}\end{array}$ \\
\hline $\begin{array}{l}\text { Colorectal } \\
\text { Esophageal } \\
\text { Stomach }\end{array}$ & $\begin{array}{l}\text { Vegetables and fruits } \\
\text { Catechins, theanine } \\
\text { Vegetables and fruits } \\
\text { Red meat and processed red meat } \\
\text { Red meat and processed red meat } \\
\text { Processed red meat } \\
\text { Coffee } \\
\text { Spices (ginger, garlic, pepper, etc.) } \\
\text { Flavonoids, isoflavones } \\
\text { Catechins, theanine } \\
\text { Spices (ginger, garlic, pepper, etc.) } \\
\text { Flavonoids, isoflavones }\end{array}$ & $\begin{array}{l}\text { Significantly reduced colon cancer risk in humans } \\
\text { Reduced colon cancer risk in humans } \\
\text { Significantly reduced colon cancer risk in humans } \\
\text { Increased colorectal cancer risk in humans } \\
\text { No association with rectal cancer risk in humans } \\
\text { Association with gastric cancer (human case-control) } \\
\text { Significantly reduced colorectal cancer risk in humans } \\
\text { Prevention, therapeutic effect on cancers in humans } \\
\text { Reduced risk of colorectal cancer } \\
\text { Reduced esophageal cancer risk in humans } \\
\text { Prevention, therapeutic effect on cancers in humans } \\
\text { Reduced stomach cancer risk in humans }\end{array}$ & $\begin{array}{l}{[11]} \\
{[22]} \\
{[15]} \\
{[16]} \\
{[16]} \\
{[17]} \\
{[19]} \\
{[24]} \\
{[35]} \\
{[22]} \\
{[24]} \\
{[35]}\end{array}$ \\
\hline Prostate & $\begin{array}{l}\text { Green tea, polyphenol EGCG } \\
\text { Eggs }\end{array}$ & $\begin{array}{l}\text { Reduced prostate cancer risk in humans } \\
\text { Possible reduced risk of prostate cancer in humans }\end{array}$ & $\begin{array}{l}{[23]} \\
{[31]}\end{array}$ \\
\hline $\begin{array}{l}\text { Ovarian } \\
\text { Endometrial }\end{array}$ & $\begin{array}{l}\text { Fiber intake } \\
\text { Eggs } \\
\text { High sugar intake } \\
\text { Isoflavones } \\
\text { Coffee } \\
\text { Isoflavones }\end{array}$ & $\begin{array}{l}\text { Dose-related reduced ovarian cancer risk in humans } \\
\text { Modest reduced ovarian cancer risk in humans } \\
\text { Higher ovarian cancer risk in African American women } \\
\text { Reduced ovarian cancer risk in humans } \\
\text { Reduced risk of endometrial cancer in humans } \\
\text { Reduced risk of endometrial cancer }\end{array}$ & $\begin{array}{l}{[32,33]} \\
{[31]} \\
{[34]} \\
{[35]} \\
{[20]} \\
{[35]}\end{array}$ \\
\hline Liver & $\begin{array}{l}\text { Coffee } \\
\text { n-3 fatty acid }\end{array}$ & $\begin{array}{l}\text { Reduced liver cancer risk in humans } \\
\text { Reduction in mortality and hospital stay in post- } \\
\text { operative cirrhotic liver cancer patients }\end{array}$ & $\begin{array}{l}{[19]} \\
{[47]}\end{array}$ \\
\hline Lung & $\begin{array}{l}\text { Flavonoids, isoflavones, } \\
\text { Cruciferous vegetables } \\
\text { Vitamin E }\end{array}$ & $\begin{array}{l}\text { Reduced lung cancer risk in humans } \\
\text { Significantly reduced lung cancer risk in non-smokers } \\
\text { Protective effect against lung cancer in humans }\end{array}$ & $\begin{array}{l}{[35]} \\
{[36]} \\
{[37]}\end{array}$ \\
\hline Pancreatic & $\begin{array}{l}\text { Folate (vegetables, fruits) } \\
\text { Red meat } \\
\text { Alcohol } \\
\text { Non-alcohol Mediterranean diet } \\
\text { B-carotene, zeaxanthin, } \alpha \text {-tocopherol }\end{array}$ & $\begin{array}{l}\text { Potentially reduced pancreatic cancer risk in humans } \\
\text { Potentially increased pancreatic cancer risk in humans } \\
\text { Increased pancreatic cancer risk after heavy drinking } \\
\text { No effect on pancreatic cancer risk in humans } \\
\text { Potentially reduced pancreatic cancer risk in humans }\end{array}$ & $\begin{array}{l}{[38,39]} \\
{[39]} \\
{[40]} \\
{[41]} \\
{[42]}\end{array}$ \\
\hline Skin & $\begin{array}{l}\text { Folate } \\
\text { Reduced Vitamin D, 25(OH)D level } \\
\text { Vitamin D and VDR } \\
\text { Proanthocyanidins }\end{array}$ & $\begin{array}{l}\text { Sun protection, reduced risk of skin cancer in humans } \\
\text { Reduced survival of melanoma patients } \\
\text { Slow-down of melanoma progression in humans } \\
\text { Potential prevention of non-melanoma cancer in } \\
\text { humans }\end{array}$ & $\begin{array}{l}{[44]} \\
{[45]} \\
{[45]} \\
{[46]}\end{array}$ \\
\hline
\end{tabular}

EGCG, epigallocatechin gallate; ER, Estrogen-receptor negative; PUFAs, poly-unsaturated fatty acids; VDR, vitamin D receptor.

In a meta-analysis of 143 studies on the association of isoflavones and flavonoids with reduced cancer risk, it was demonstrated that isoflavones were associated with a significantly reduced risk of lung and stomach cancers [35]. In contrast, total flavonoids were demonstrated to be associated with a non-significant decrease in the risk of breast cancer. Case-control studies revealed that total flavonoids and individual classes of flavonoids were associated with the 
reduction in the risk of the aero-digestive tract, colorectal, breast, and lung cancers. Similarly, isoflavones were reported to reduce the risk of ovarian, breast, colorectal, endometrial, and lung cancers. In another study conducted on lung cancer risk in Japan, no significant effect of the consumption of cruciferous vegetables rich in isothiocyanates was observed [36]. However, including smoking as a factor in the study revealed a significant association between cruciferous vegetables and lung cancer risk. Furthermore, a meta-analysis revealed a link between vitamin $E$ intake and reduced lung cancer risk [37]. It was established that the risk of lung cancer decreased by $3 \%$ with every $2 \mathrm{mg} /$ day increase in dietary vitamin $\mathrm{E}$.

In the case of pancreatic cancer, the consumption of vegetables, fruits, and whole grains has been associated with a reduced risk of disease [38]. The combination of whole grains and folate has been indicated to provide further protection against pancreatic cancer, while it was suggested to replace meat cooked at high temperatures with fish or poultry due to the negative effects exerted by the former [38, 39]. Although moderate alcohol consumption has been associated with a decreased risk of pancreatic cancer, heavy drinking has been reported to enhance the risk [40]. In contrast, no association was discovered between an alcohol-free diet and reduced risk of pancreatic cancer in the EPIC study conducted with half a million participants across ten European countries [41]. A comparison study of exocrine pancreatic cancer patients and healthy volunteers demonstrated an association of the reduced risk of pancreatic cancer in individuals with high plasma concentrations of $\beta$-carotene, zeaxanthin, and $\alpha$-tocopherol [42].

In the context of skin cancer, a dramatic increase was reported in disease incidence with enhanced exposure to UV light, reaching levels equivalent to those of the malignancies in all the other organs combined [43]. Folate has been proposed to perform a critical role in skin cancer prevention by potentially providing protection to the sun-exposed skin [44]. As large-scale epidemiological studies have indicated that a decrease in folate levels may increase the risk of skin cancer, topical folate delivery may provide protection. Vitamin D has exhibited anti-carcinogenic and anti-melanoma effects in animal models, providing photoprotection against UVB-induced damage [45]. The vitamin D receptor (VDR) or the retinoic acid orphan receptors (ROR)- $\alpha$ or ROR- $\nu$ have been identified as mediators. In melanoma patients, low levels of hydroxylated vitamin D, 25 $(\mathrm{OH}) \mathrm{D}$, which is the most stable vitamin $\mathrm{D}$ metabolite and also a precursor of the biologically active $1,25(\mathrm{OH}) 2 \mathrm{D}$, have been reported to serve as an indication of reduced survival. Moreover, the progression of melanoma was observed to slow down with the overexpression of ROR- $\alpha$ or ROR- $\psi$. In the case of non-melanoma skin cancer, grape seed proanthocyanidins have exhibited significant inhibition of the growth of skin tumors in animal models through the promotion of damaged DNA repair and the stimulation of the immune system, a mechanism that holds promise for the prevention of excessive exposure to solar UVB radiation and the reduction of the risk of nonmelanoma skin cancer in humans [46]. Finally, reductions in overall mortality and length of hospital stay in cirrhotic patients with liver cancer recovering from surgery were observed to be significantly improved upon dietary supplementation of n-3 fatty acid [47].

Data obtained from epidemiological and nutritional intervention studies have led to a better understanding of the impact of nutrition on disease treatment [48]. In this context, bioactive nutrients have been reported to play a vital role in affecting immune responses, while dietary nutrients have been reported to control inflammatory and pro-tumorigenic responses of the immune cells [49]. For instance, metabolic pathway-related nutrients, such as glutamine, arginine, vitamin, minerals, and long-chain fatty acids, have been indicated as immunonutrients capable of 
providing immunoprevention and immune-modulating effects for the reduction of risk of cancer and for cancer treatment. Moreover, dietary-derived agents have been identified to possess activity against cancer stem-like cells, which are highly tumorigenic and chemotherapy-resistant and are also associated with cancer recurrence [50]. Targeting cancer stem-like cells may serve as a novel approach to cancer prevention with a low toxicity therapeutic strategy. Potential bioactive agents include resveratrol, vitamin A, EGCG, vitamin A, flavonoids, isothiocyanates, and curcumin. One area of concern related to the application of bioactive food compounds is their poor bioavailability which decreases their therapeutic potency [51]. This concern has been addressed by novel formulations of bioactive compounds that are based on nanoparticles, providing controlled and sustained release.

In the context of disease prevention and treatment, it is appropriate to discuss dietary interventions. Specific diets such as the Mediterranean diet have been reported to support the reduction in the risk of cardiovascular disease [52] and neurodegeneration [53], while the DASH (Dietary Approaches to Stop Hypertension) diet was demonstrated to reduce blood pressure [54] and coronary heart disease [55]. Moreover, the vegetarian [56], Japanese [57], and Nordic [58] diets have all been demonstrated to contribute to lowering of blood pressure. The Paleo diet was reported to provide metabolic balance in type 2 diabetes mellitus patients [59]. The Mediterranean [60] and vegetarian diets [61] were suggested to reduce cancer risk and cancer mortality, respectively.

\section{Cancer and Genetics}

The etiology of cancer was originally postulated to be based on mutagenesis leading to uncontrolled cell growth and tumor formation [62]. Although most of the cancers are induced by exposure to environmental, lifestyle, or behavioral factors, a minority of them are caused by inherited genetic mutations [63]. The two categories of genes affected in such cases are oncogenes and tumor suppressor genes. Proto-oncogenes play an integral role in cell growth and differentiation and may be activated to give rise to oncogenes as a result of point mutations, deletions, amplifications, and chromosomal translocation, leading to uncontrolled tumor growth [64]. Tumor-suppressor genes inhibit cell division, and when subjected to genetic changes, promote cancer development [65]. In regard to cancer development, it has been postulated that most genes require two mutations for a phenotypic change to manifest, as reported first by Knudson in 1971 [66], which indirectly led to the identification of cancer-related genes. However, since some individuals have inherited mutations in certain genes of theirs, they are at a higher risk of developing cancer, as presented in the examples below.

Lobular breast cancer susceptibility has been reported to be associated with genetic risk factors, which mainly comprise the four high-penetrance genes, namely, BRCA1, BRCA2, TP53, and CDH1 [67]. Germline mutations in BRCA1 and TP53 have mostly been associated with invasive ductal carcinoma, while mutations in BRCA2 have been linked to both ductal and lobular cancers. Mutations in $\mathrm{CDH} 1$ have been associated with invasive lobular carcinoma and not with ductal carcinoma. As the risk of lobular carcinoma in female mutation carriers is approximately $50 \%$, there is a strong requirement of intensive breast cancer screening through annual magnetic resonance imaging and mammograms. 
Another area of genetics that is associated with cancer is gene polymorphism and its susceptibility to colon cancer in the context of environmental factors such as nutrition [68]. In particular, the association between red meat consumption and the development of colon cancer, and the presence of single nucleotide polymorphisms (SNPs) in the coding genes of the proteins involved in the metabolism of nutrients have been investigated [68]. It has been demonstrated that gene polymorphisms might have a role to play in colorectal cancer risk in individuals consuming large quantities of red meat. Therefore, dietary recommendations should consider individual genotype differences while applying nutritional genomics for personalized preventive and therapeutic intervention in colon cancer patients. In another approach, the potential association between dietary acrylamide intake and the genes related to ovarian cancer risk was addressed [69]. A study conducted with 62,573 women, concerning the genes involved in acrylamide metabolism and acrylamide-induced carcinogenesis, revealed 57 SNPs and two gene deletions, although no statistically significant interactions between acrylamide and the gene variants were observed. However, several nominally statistically significant interactions between acrylamide intake and SNPS in the HSD3B1/B2 gene cluster were detected. Moreover, SNPs in the $V D R$ and the vitamin D-binding protein (VDP) genes have been demonstrated to affect melanomagenesis and the disease outcome in melanoma patients [45].

In another effort to better understand the impact of genetics on cancer development, the comprehensive database for cancer-related somatic mutations, CSOMIC, has been expanded to include structural information of proteins encoded by cancer-related genes (COSMIC-3D) [70]. In contrast to previous approaches based on the analysis of single domains in large proteins, greater than $60 \%$ of the genes in the Cancer Gene Census were predicted to contain multiple domains. Another drawback is the lack of structural information in public databases, as among the 469 structures available for gene products, $90 \%-100 \%$ structural information is available for only 87 . In this context, protein structure modeling based on the two in-house methods, SDM2 and mCSM, has been utilized for the investigation of the effects of mutations.

\section{Cancer and Epigenetics}

Epigenetic modifications may be defined as reversible changes in gene expression without affecting the primary DNA sequence [71]. DNA methylation [72], histone modifications [73], and RNA interference (RNAi) [74] represent the main epigenetic mechanisms, all demonstrating association with cancer development. In regard to DNA methylation, the addition of methyl groups $\left(\mathrm{CH}_{3}\right)$, clustered in promoter regions, affects the regulation of gene expression by down- or up-regulating mRNA transcription [75]. Hypermethylation of several tumor-suppressor genes in their promotion regions has been associated with gene activation and cancer development [76, 77]. For instance, DNA hypermethylation has been associated with endometrial [78], breast [79], prostate [80], and rectal cancer [81]. Interestingly, individuals infected with Helicobacter pylori exhibit higher methylation levels, which might be the reason underlying the documented enhanced risk of gastric cancer in these individuals [82]. Another issue of importance concerns the impact of physical activity. It has been indicated that exercise influenced the reduced risk of cancer through increased global DNA methylation [83]. Several cancer drugs based on DNA methyltransferase (DNMT) inhibitors such as zebularine have been developed [84] (Table 2). A novel inhibitor of DNMT, named n-butylidenephatlide (n-BP), isolated from a Chinese herb, has 
been reported to exhibit dose- and time-dependent inhibition of DNA methyltransferase 1 (DNMT1) [85]. Pancreatic ductal adenocarcinoma (PDAC) cells were suppressed by n-BP, PDAC tumor growth was inhibited, and survival was prolonged in BALB/c mice. Furthermore, decitabine has received approval for use in the treatment of acute myeloid leukemia (AML) in South Korea [86].

Table 2 Examples of epigenetic drugs.

\begin{tabular}{|c|c|c|c|c|}
\hline Drug & Disease & Phase & Application/Therapeutic effect & Ref \\
\hline $\begin{array}{l}\text { DNMT Inhibitor } \\
\text { Zebularine } \\
\text { n-BP } \\
\text { Decitabine }\end{array}$ & $\begin{array}{l}\text { T-cell Lymphoma } \\
\text { PADC } \\
\text { AML }\end{array}$ & $\begin{array}{l}\text { Preclinical } \\
\text { Preclinical } \\
\text { FDA, EMEA approved }\end{array}$ & $\begin{array}{l}\text { Antitumor activity, low toxicity } \\
\text { Tumor inhibition, prolonged survival } \\
\text { Treatment of AML }\end{array}$ & $\begin{array}{l}{[84]} \\
{[85]} \\
{[86]}\end{array}$ \\
\hline $\begin{array}{l}\text { HDAC inhibitor } \\
\text { Vorinostat } \\
\text { Romidepsin } \\
\text { Belinostat } \\
\text { Panobilostat }\end{array}$ & $\begin{array}{l}\text { CTCL } \\
\text { CTCL, PTCL } \\
\text { PTCL } \\
\text { Multiple myeloma }\end{array}$ & $\begin{array}{l}\text { FDA approved } \\
\text { FDA approved } \\
\text { FDA, EMEA approved } \\
\text { FDA approved }\end{array}$ & $\begin{array}{l}\text { Treatment of CTCL } \\
\text { Treatment of CTCL and PTCL } \\
\text { Treatment of refractory PTCL } \\
\text { Treatment of multiple myeloma }\end{array}$ & $\begin{array}{l}{[92]} \\
{[93]} \\
{[94]} \\
{[95]}\end{array}$ \\
\hline $\begin{array}{l}\text { RNA interference } \\
\text { miR-193-3a } \\
\text { anti-PLK1 siRNA }\end{array}$ & $\begin{array}{l}\text { Cancer } \\
\text { ACC }\end{array}$ & $\begin{array}{l}\text { Preclinical } \\
\text { Phase I/II }\end{array}$ & $\begin{array}{l}\text { Effect on apoptosis, metastasis } \\
\text { Good tolerance, anticancer activity }\end{array}$ & $\begin{array}{l}{[100]} \\
{[102]}\end{array}$ \\
\hline $\begin{array}{l}\text { Combination } \\
\text { DNMT + HDAC } \\
\text { DNMT + HDAC } \\
\text { Anti-KRAS siRNA + } \\
\text { gemcitabine }\end{array}$ & $\begin{array}{l}\text { Esophageal cancer } \\
\text { CTCL } \\
\text { LAPC }\end{array}$ & $\begin{array}{l}\text { Preclinical } \\
\text { Phase I } \\
\text { Phase I/Ila }\end{array}$ & $\begin{array}{l}\text { Apoptosis, decreased cell migration } \\
\text { Safe administration } \\
\text { Stable disease in LAPC patients }\end{array}$ & $\begin{array}{l}{[88]} \\
{[103]} \\
{[105]}\end{array}$ \\
\hline
\end{tabular}

ACC, adrenocortical cancer; AML, acute myeloid leukemia; CTCL, cutaneous T-cell lymphoma; LAPC, local advanced pancreatic cancer; n-BP, butylidenephtalide; PLK1, polo-like kinase 1; PTCL, peripheral T-cell lymphoma; siRNA, small interfering RNA.

In regard to histone modifications, it has been reported that acetylation, methylation, ubiquitination, and phosphorylation are able to repress or activate transcription [87, 88]. Typically, histone acetylation has been demonstrated to influence the expression of oncogenes, tumorsuppressor genes, and DNA-repair genes [72]. For instance, enhanced acetylation of histone 3 lysine 27 (H3K27) in esophageal cancer cells has been documented [89]. The histone deacetylase (HDAC) inhibitor named MPTOG030 has exhibited anti-cancer activity in vivo in HT29 tumor xenograft models, suggesting a great potential for its use in colorectal cancer therapy [90]. Moreover, HDAC inhibitors, such as vorinostat, romidepsin, belinostat, panobinostat, entinostat, and chidamide, have been utilized in the treatment of non-Hodgkin's lymphoma (NHL) and have exhibited promising clinical responses in patients with relapsed/refractors NHL [91]. Several drugs, such as vorinostat for the treatment of cutaneous T-cell lymphoma (CTCL) [92], romidepsin for CTCL and peripheral T-cell lymphoma (PTCL) [93], belinostat for relapsed or refractory PTCL [94], and panobinostat for multiple myeloma [95], have been approved by the FDA. 
Long non-coding RNAs (ncRNAs) and micro-RNAs (miRNAs) represent the third epigenetic mechanism [74]. The importance of miRNAs may be ascertained by the facts such as the identification of greater than 800 miRNAs in humans, greater than $3 \%$ of the human genes coding for miRNAs, and $40 \%-90 \%$ of the human proteins being regulated by miRNAs [96, 97]. MiRNAs are able to interact with the mRNA target sequences, resulting in mRNA degradation or suppression of translation [97]. The reversible nature of miRNAs has led to the development of miRNA-based drugs against cancer [98]. For instance, miRNAs have been used to target tumor-suppressor mRNAs or oncogene mRNAs [99]. The tumor-suppressor miRNA named miR-193a-3p has been demonstrated to affect proliferation, apoptosis, migration, invasion, and metastasis [100]. In another approach, it was demonstrated that HDAC inhibitors could modulate miR-200 expression, presenting a novel strategy having the potential for breast cancer treatment [101]. In a phase I-II clinical trial conducted with patients having refractory adrenocortical cancer (ACC), a lipid nanoparticle formulation of a small interfering RNA (siRNA) was well tolerated and exhibited preliminary anti-cancer activity [102].

Various combination therapies have also been conducted. In this context, DNMT and HDAC inhibitors were combined for the treatment of esophageal squamous cell carcinoma (ESCC), resulting in induction of DNA damage, apoptosis, and reduced cell viability [88]. Studies conducted with ESCC and esophageal adenocarcinoma (EAC) cells, in vitro as well as in human esophageal carcinomas, demonstrated decreased cell migration. Furthermore, the combination of the DNMT inhibitor hydralazine-valproate and an HDAC inhibitor were applied for the treatment of CTCL [103]. The phase I trial confirmed safe drug administration, although additional studies are required to demonstrate efficacy. Moreover, combination therapy of vorinostat with the tyrosine kinase inhibitor dasatinib exerted a synergistic effect of enhanced cell cycle arrest and decreased $\mathrm{BCl}-2$ expression in human MCF-7 breast cancer cells [104]. A siRNA targeting the Kirsten rat sarcoma viral oncogene (K-Ras) was combined with gemcitabine for slow release from a biodegradable implant, in a phase $\mathrm{I} /$ Ila clinical trial, in patients with non-operable local advanced pancreatic cancer (LAPC) [105]. No tumor progression was observed in CT scans in 12 out of 15 patients, stable disease condition was obtained in 10 individuals, and two patients exhibited partial response.

Another approach to cancer therapy involves the combination of immunotherapy and epigenetic drugs [106]. It has been demonstrated that epigenetic drugs such as DNMT inhibitors are able to up-regulate immune signaling in epithelial cancer cells through demethylation of endogenous retroviruses and cancer/testis antigens [106]. This approach may involve induction of interferon pathways by double-stranded RNA (dsRNA) transcripts and enhancement of immune checkpoint efficacy, providing a novel potent strategy for cancer therapy.

Recently, epigenetic changes in relation to cancer and aging have received increasing attention [107]. Several bioactive phytochemicals have demonstrated modulatory activities in multiple cancers, and when used in combination with dietary interventions such as calorie restriction, have been reported to delay aging and minimize the risk of cancer in both preclinical and clinical settings. Therefore, these phytochemicals could be applied for cancer prevention and therapy either alone or in combination with existing drugs. Moreover, a growing number of epigenetic changes have been identified to be involved in the regulation of genes associated with breast tumor growth and metastasis [108]. Another finding of importance is that several phytochemicals, such as those in green tea, polyphenols, curcumin, genistein, resveratrol, and sulforaphane, 
induce epigenetic modifications in various types of cancer, including breast cancer. It is, therefore, obvious that dietary choices play an important role in cancer prevention and therapeutic interventions related to cancers.

\section{Conclusions}

The impact of nutrition on health, disease prevention, and treatment is huge, with the indication that up to two-thirds of deaths caused by cancer could be prevented through dietary interventions and lifestyle changes. Several dietary components have been demonstrated to reduce the risk of cancer. As summarized in Table 1, specific dietary intakes may reduce the risk of various types of cancer, while consumption of certain nutrients may increase the disease risk. In general, diets rich in vegetables and fruits have been reported to provide both prophylactic and therapeutic efficacy. In contrast, diets with a high content of red meat have been demonstrated to increase the risk of various types of cancer. However, the real scenario is not all black and white, encouraging the designing of a large number of "healthy" diets. Although a few of these diets are based on a completely vegetarian set up, certain others emphasize the consumption of red meat in moderate levels. Similarly, the favorable effect of a moderate intake of alcohol on health has been indicated in certain studies.

The impact of genetics on cancer development has been well documented, including the association of gene mutations, for example, mutations in the BRCA genes, with breast cancer. Moreover, gene polymorphism in the form of SNPs may have a role in colorectal cancer risk, especially in individuals consuming red meat in large quantities. In another approach, the induction of carcinogenesis has been described for SNPs after dietary intake of acrylamides. CSOMIC, the comprehensive database for cancer somatic mutations, serves as a great asset for research conducted in the integrated field of genetics and cancer development.

In the context of epigenetics, the main epigenetic mechanisms, namely, DNA methylation, histone modifications, and RNAi, have all been associated with cancer development. Moreover, nutrition has been demonstrated to induce epigenetic changes. In this context, DMNT and HDAC inhibitors have been demonstrated to exhibit efficacy in the treatment of different types of cancer. Furthermore, the DMNT inhibitor named decitabine has been approved for AML therapy, and the HDAC inhibitor named vorinostat has been approved for the treatment of CTCL. Drugs based on miRNAs and siRNAs are currently in preclinical and clinical trials, respectively. Combination therapy using DNMT with HDAC inhibitors and siRNA with gemcitabine in CTCL and LPAC patients, respectively, has reached the clinical trial stage. Since bioactive phytochemicals are responsible for epigenetic modifications in various cancers, they represent an attractive alternative for the prevention and treatment of cancer.

\section{Author Contributions}

Kenneth Lundstrom is the sole contributor to this work.

\section{Funding}

No funding was received for the authoring of this review. 


\section{Competing Interests}

The author has declared that no competing interests exist.

\section{References}

1. Lundstrom K. Epigenetics, nutrition, disease and drug development. Curr Drug Discov Technol. 2018; 15: Apr 19. doi: 10.2174/1570163815666180419154954. [Epub ahead of print].

2. Boeing H. Nutritional epidemiology: New perspectives for understanding the diet-disease relationship? Eur J Clin Nutr. 2013; 67: 424-429.

3. Webb D, Leahy MM, Milner JA, Allison DB, Dodd KW, Gaine PC, et al. Strategies to optimize the impact of nutritional surveys and epidemiological studies. Adv Nutr. 2013; 4: 545-547.

4. Willett WC. Diet and health: What should we eat? Science. 1995; 264: 532-537.

5. McCullough ML, Feskanich D, Stampfer MJ, Giovannucci EM, Rimm EB, Hu FB, et al. Diet quality and major chronic disease risk in men and women: Moving toward improved dietary guidance. Am J Clin Nutr. 2002; 76: 1261-1271.

6. Ornish D, Magbanua MJ, Weidner G, Weinberg V, Kemp C, Green C, et al. Changes in prostate gene expression in men undergoing an intensive nutrition and lifestyle intervention. Proc Natl Acad Sci USA. 2008; 105: 8369-8374.

7. Doll R, Peto R. The causes of cancer: Quantitative estimates of avoidable risks of cancer in the United States today. J Natl Cancer Inst. 1981; 66: 1191-1308.

8. World Cancer Research Fund, American Institute of Cancer Research, Diet, Nutrition and Prevention of Human Cancer: A Global Perspective, World Cancer Research Fund, Washington, American Institute of Cancer Research, 2007.

9. Ouédraogo $M$, Charles $C$, Ouédraogo $M$, Guisseou IP, Stévigny C, Duez P. An overview of cancer chemopreventive potential and safety of proanthocyanidins. Nutr Cancer. 2011; 63: 1163-1173.

10. Saneei P, Willett W, Esmailizadeh A. Red and processed meat consumption and risk of glioma in adults: A systematic review and meta-analysis of observational studies. J Res Med Sci. 2015; 20: 602-612.

11. Jeurnink S, Büchner FL, Bueno-de-Mesquita HB, Siersema PD, Boshuizen HC, Numans ME, et al. Variety in vegetable and fruit consumption and the risk of gastric and esophageal cancer in the European Prospective investigation into cancer and nutrition (EPIC). Int J Cancer. 2012; 131: E963-E973.

12. Dong JY, He K, Wang P, Qin LQ. Dietary fiber intake and risk of breast cancer: A meta-analysis of prospective cohort studies. Am J Clin Nutr. 2011; 94: 900-905.

13. Dong JY, Zhang L, He K, Qin LQ. Dairy consumption and risk of breast cancer: A meta-analysis of prospective cohort studies. Breast Cancer Res Treat. 2011; 127: 23-31.

14. Lian $W$, Wang $R$, Xing B, Yao Y. Fish intake and the risk of brain tumor: A meta-analysis with systematic review. Nutr J. 2017; 16: 1. doi: 10.1186/s12937-016-0223-4.

15. Annema N, Heyworth JS, McNaughton SA, lacopetta B, Fritschi L. Fruit and vegetable consumption and the risk of proximal colon, distal colon, and rectal cancers in a case-control study in Western Australia. J Am Diet Assoc. 2011; 111: 1479-1490. 
16. Zhao Z, Feng Q, Yin Z, Shuang J, Bai B, Yu P, et al. Red and processed meat consumption and colorectal cancer risk: A systematic review and meta-analysis. Oncotarget. 2017; 8: 8330683314.

17. Zhao Z, Yin Z, Zhao Q. Red and processed meat consumption and gastric cancer risk: $A$ systematic review and meta-analysis. Oncotarget. 2017; 8: 30563-30575.

18. Soares PV, Kannen V, Jordao Junior AA, Garcia SB. Coffee, but neither decaffeinated coffee nor caffeine, elicits chemoprotection against a direct carcinogen in the colon of wistar rats. Nutr Cancer. 2018; 26: 1-9.

19. Bohn SK, Blomhoff R, Paur I. Coffee and cancer risk, epidemiological evidence, and molecular mechanisms. Mol Nutr Food Res. 2014; 58: 915-930.

20. Lafranconi A, Micek A, Galvano F, Rossetti S, Del Pup L, Beretta M, et al. Coffee decreases the risk of endometrial cancer: A dose-response meta-analysis of prospective cohort studies. Nutrients. 2017; 9: pii: E1223.

21. Zamora-Ros R, Alghamidi MA, Cayssials V, Franceschi S, Almquist M, Hennings J,et al. Coffee and tea drinking in relation to the risk of differentiated thyroid carcinoma: Results from the European Prospective Investigation into Cancer and Nutrition (EPIC) study. Eur J Nutr. 2018; 110. doi: 10.1007/s00394-018-1874-z. [Epub ahead of print].

22. Cooper R. Green tea and theanine: health benefits. Int J Food Sci Nutr. 2012; 63: 90-97.

23. Lee PMY, Ng CF, Liu ZM, Ho WM, Lee MK, Wang F, et al. Reduced prostate cancer risk with green tea and epigallocatechin-3 gallate intake among Hong Kong Chinese men. Prostate Cancer Prostatic Dis. 2017; 20: 318-322.

24. Zheng J, Zhou Y, Li Y, Xu D-P, Li S, Li H-B. Spices for prevention and treatment of cancer. Nutrients. 2016; 8: pii: E495.

25. Harnden KK, Blackwell KL. Increased fiber intake decreases premenopausal breast cancer risk. Pediatrics. 2016; 137: e20154376.

26. Farvid MS, Eliassen AH, Cho E, Liao X, Chen WY, Willett WC. Dietary fiber intake in young adults and breast cancer risk. Pediatrics. 2016; 137: e20151226.

27. Dong JY, Qin LQ. Soy isoflavones consumption and risk of breast cancer incidence or recurrence: A meta-analysis of prospective studies. Breast Cancer Res Treat. 2011; 125: 315323.

28. Farvid MS, Chen WY, Michels KB, Choe E, Willett WC, Eliassen AH. Fruit and vegetable consumption in adolescence and early adulthood and risk of breast cancer: Population-based cohort study. BMJ. 2016; 353: i2343.

29. Jamshidinaeini $Y$, Akbari $M$, Abdollahi $M$, Adami N, Davoodi SH. Vitamin D status and risk of breast cancer in Iranian women: A case-control study. J Am Coll Nutr. 2016; 35: 639-646.

30. Hidaka BH, Kimler BF, Fabian CJ, Carlson SE. An empirically derived dietary pattern associated with breast cancer risk is validated in a nested case-control cohort from a randomized primary prevention trial. Clin Nutr ESPEN. 2017; 17: 8-17.

31. Keum N, Lee D, Marchand N, Oh H, Liu H, Aune D, et al. Egg intake and cancers of the breast, ovary and prostate: A dose-response meta-analysis of prospective observational studies. $\mathrm{Br} \mathrm{J}$ Nutr. 2015; 114: 1099-1107.

32. Xu H, Ding $Y$, Xin $X$, Wang $W$, Zhang $D$. Dietary fiber intake is associated with a reduced risk of ovarian cancer: A dose-response meta-analysis. Nutr Res. 2018; 57: 1-11. 
33. Qin B, Moorman PG, Kelemen LE. Alberg AJ, Barnholz-Sloan JS, Bondy M, et al. Dietary quality and ovarian cancer risk in African American women. Am J Epidemiol. 2017; 185: 1281-1289.

34. Qin B, Moorman PG, Alberg AJ, Barnholtz-Sloan JS, Bondy M, Cote $M$, et al. Dietary carbohydrate intake, glycaemic load, glycaemic index and ovarian cancer risk in African American women. Br J Nutr. 2016; 115: 694-702.

35. Grosso G, Godos J, Lamuela-Raventos R, Ray S, Micek A, Pajak A, et al. A comprehensive metaanalysis on dietary flavonoid and lignan intake and cancer risk: Level of evidence and limitations. Mol Nutr Food Res. 2017; 61: doi: 10.1002/mnfr.201600930.

36. Mori N, Shimazu T, Sasazuki S, Nozue M, Mutoh M, Sawada N, et al. Cruciferous vegetable intake is inversely associated with lung cancer risk among current nonsmoking men in the Japan Public Health Center Study. J Nutr. 2017; 147: 841-849.

37. Zhu YJ, Bo YC, Liu XX, Qui CG. Association of dietary vitamin E intake with risk of lung cancer: $A$ dose-response meta-analysis. Asia Pac J Clin Nutr. 2017; 26: 271-277.

38. Pericleous M, Rossi RE, Mandair D, Whyand T, Caplin ME. Nutrition and pancreatic cancer. Anticancer Res. 2014; 34: 9-21.

39. Weisbeck A, Jansen RJ. Nutrients and the pancreas: An epigenetic perspective". Nutrients. 2017; 9: pii: E283. doi: 10.3390/nu9030283.

40. Lu PY, Shu L, Shen SS, Chen XJ, Zhang XY. Dietary patterns and pancreatic cancer risk: A metaanalysis. Nutrients. 2017; 9: pii: E38.

41. Molina-Montes, E, Sanchez, MJ, Buckland, G, Bueno-de-Mosquita HB, Weiderpass E, Amiano P, et al. Mediterranean diet and risk of pancreatic cancer in the European Prospective Investigation into Cancer and Nutrition cohort. Br J Cancer. 2017; 116: 811-820.

42. Jeurnink SM, Ros MM, Leenders M, van Duijnhoven FJ, Siersema PD, Jansen EH, et al. Plasma carotenoids, vitamin $\mathrm{C}$, retinol and tocopherol levels and pancreatic cancer risk within the European Prospective Investigation into Cancer and Nutrition: A nested case-control study: Plasma micronutrients and pancreatic cancer risk. Int J Cancer. 2015; 136: E665-E676.

43. Katiyar SK. Dietary proanthocyanidins inhibit UV radiation-induced skin tumor development through functional activation of the immune system. Mol Nutr Food Res. 2016; 60: 1374-1382.

44. Williams JD, Jacobson EL, Kim H, Kim H, Jacobson MK. Folate in skin cancer prevention. Subcell Biochem. 2012; 56: 181-197.

45. Slominski AT, Brozyna AA, Zmijewski MA, Jozwicki W, Jetten AM, Mason RS, et al. Vitamin D signalling and melanoma: Role of vitamin $\mathrm{D}$ and its receptors in melanoma progression and management. Lab Invest. 2017; 97: 706-724.

46. Katiyar SK, Pal HC, Prasad R. Dietary proanthocyanidins prevent ultraviolet radiation-induced non-melanoma skin cancer through enhanced repair of damaged DNA-dependent activation of immune sensitivity. Semin Cancer Biol. 2017; 46: 138-145.

47. Zhang B, Wei G, Li R, Wang Y, Yu J, Wang R, et al. N-3 fatty acid-based parenteral nutrition improves postoperative recovery for cirrhotic patients with liver cancer: A randomized controlled clinical trial. Clin Nutr. 2017; 36: 1239-1244.

48. Adhami VM, Mukhtar H. Nutrition in the cause and prevention of cancer: An update. Mol Nutr Food Res. 2016; 60: 1226-1227.

49. Janakiram NB, Mohammed A, Madka V, Kumar G, Rao CV. Prevention and treatment of cancers by immune modulating nutrients. Mol Nutr Food Res. 2016; 60: 1275-1294. 
50. Khan S, Karmokar A, Howells L, Thomas AL, Bayliss R, Gescher A, et al. Targeting cancer stemlike cells using delay-derived agents - Where are we now? Mol Nutr Food Res. 2016; 60: 12951309.

51. Mukherjee PK, Harwansh RK, Battacharyya S. Bioavailability of herbal products: Approach toward improved pharmacokinetics. In Evidence-based Validation of Herbal Medicine (Ed. Mukherjee PK). Elsevier. 2015; 217-245.

52. Schwingshackl L, Hoffmann G. Monounsaturated fatty acids, olive oil and health status: $A$ systematic review and meta-analysis of cohort studies. Lipids Health Dis. 2014; 13: 154.

53. Psaltopoulou T, Kosti RI, Haidopoulos D, Dimopoulos M, Panagiotakos DB. Olive oil intake is inversely related to cancer prevalence: A systematic review and a meta-analysis of 13,800 patients and 23,340 controls in 19 observational studies. Lipids Health Dis. 2011; 10: 27.

54. Lung $\mathrm{NH}$, Institute B. Your guide to lowering your blood pressure with dash. Bethesda (MD). 2006.

55. Miller ER 3rd, Erlinger TP, Appel LJ. The effects of macronutrients on blood pressure and lipids: An overview of the DASH and OmniHeart trials. Curr Atheroscler Rep. 2006; 8: 460-465.

56. Wang F, Zheng J, Yang B, Jiang J, Fu Y, Li D. Effects of vegetarian diets on blood lipids: A systematic review and meta-analysis of randomized controlled trials. J Am Heart Assoc. 2015; 4: e002408.

57. Rivas M, Garay RP, Escanero JF, Cia P Jr., Cia P, Alda JO. Soymilk lowers blood pressure in men and women with mild to moderate essential hypertension. J Nutr. 2002; 132: 1900-1902.

58. Adamsson V, Reumark A, Fredriksson IB, Hammarström E, Vessby B, Johansson G, et al. Effects of a healthy Nordic diet on cardiovascular risk factors in hypercholesterolaemic subjects: $A$ randomized controlled trial (NORDIET). J Intern Med. 2011; 269: 150-159.

59. Otten J, Stomby A, Waling $M$, Isaksson A, Söderström I, Ryberg $M$, et al. Benefits of a Paleolithic diet with and without supervised exercise on fat mass, insulin sensitivity, and glycemic control: A randomized controlled trial in individuals with type 2 diabetes. Diabetes Metab Res Rev. 2017; 33: e2828. doi: 10.1002/dmrr.2828.

60. Buckland G, Gonzalez CA. The role of olive oil in disease prevention: A focus on the recent epidemiological evidence from cohort studies and dietary intervention trials. Br J Nutr. 2015; 113 Suppl 2: S94-S101.

61. Appleby PN, Crowe FL, Bradbury, KE Travis RC, Key TJ. Mortality in vegetarians and comparable nonvegetarians in the United Kingdom. Am J Clin Nutr. 2016; 103: 218-230.

62. Stewart B, Wild C. Cancer etiology. World cancer report. WHO. 2014.

63. Roukos DH. Genome-wide association studies: How predictable is a person's cancer risk? Exp Rev Anticancer Ther. 2009; 9: 389-392.

64. Bell JC. Oncogenes. Cancer Lett. 1988; 40: 1-5.

65. Sherr CJ. Principles of tumor suppression. Cell. 2004; 116: 235-246.

66. Knudson A. Mutation and cancer: Statistical study of retinoblastoma. Proc Natl Acad Sci USA. 1971; 68: 820-823.

67. Dossus L, Benusiglio PR. Lobular breast cancer: Incidence and genetic and non-genetic risk factors. Breast Cancer Res. 2015; 13: 37. doi: 10.1186/s13058-015-0546-7.

68. Doaei S, Hajiermaeil M, Aminifard A, Mosavi-Jarrahi SA, Akbani ME, Gholamalizadeh M. Effects of gene polymorphisms of metabolic enzymes on the association between red and 
processed meat consumption and the development of colon cancer; a literature review. J Nutr Sci. 2018; 7: e26. doi:10.1017/jns.2018.17.

69. Hogervorst JGF, van den Brandt PA, Godschalk RWL, van Shooten FJ, Schouten LJ. Interactions between dietary acrylamide intake and genes for ovarian cancer risk. Eur J Epidemiol. 2017; 32: 431-441.

70. Malhotra $S$, Alsulami AF, Heiyun $Y$, Ochoa BM, Jubb $H$, Forbes $S$, et al. Understanding the impacts of missense mutations on structures and functions of human cancer-related genes: $A$ preliminary computational analysis of the COSMIC Cancer Gene Census. PLoS One. 2019; 14: e0219935. doi: 10.1371/journal.pone.0219935.

71. Su L, Mahabir S, Ellison GL, McGuinn LA, Reid BC. Epigenetic contributions to the relationship between cancer and dietary intake of nutrients, bioactive food components and environmental toxicants. Front Genet. 2012; 2: 91. doi:10.3389/fgene.2011.00091.

72. Gnyszka A, Jastrzebski Z, Flis S. DNA methyltransferase inhibitors and their emerging role in epigenetic therapy of cancer. Anticancer Res. 2013; 33: 2989-2996.

73. Harrison IF, Dexter DT. Epigenetic targeting of histone deacetylase: Therapeutic potential in Parkinson's disease? Pharmacol Ther. 2014; 140: 34-52.

74. Lundstrom K. MicroRNA in disease and gene therapy. Curr Drug Discov Technol. 2011; 8: 7686.

75. Fang M, Chen D, Yang CS. Dietary polyphenols may affect DNA methylation. J Nutr. 2007; 137: 223S-228S.

76. Boehm TM, Drahovsky D. Alteration of enzymatic methylation of DNA cytosines by chemical carcinogens; a mechanism involved in the initiation of carcinogenesis. J Natl Cancer Inst. 1983; 71: 429-433.

77. Costello JF, Plass C. Methylation matters. J Med Genet. 2001; 38: 285-303.

78. Banno X, Yanokura M, lida M, Masuda K, Aoki D. Carcinogenic of endometrial cancer: Involvement of genetics and epigenetics. J Obstet Gynealog Res. 2014; 40: 1957-1967.

79. Wang F, Yang Y, Fu Z, Xu N, Chen F, Yin H, et al. Differential DNA methylation status between breast carcinomatous and normal tissues. Biomed Pharmacother. 2014; 68: 699-707.

80. Brocks D, Assenov Y, Minner S, Bogatyrova O, Simon R, Koop C, et al. Intratumor DNA methylation heterogeneity reflects clonal evolution in aggressive prostate cancer. Cell Rep. 2014; 8: 798-806.

81. Benard A, Zeestraten EC, Goossens-Beumer IJ, Putter H, van de Velde CJ, Hoon DS, et al. DNA methylation of apoptosis genes in rectal cancer predicts patient survival and tumor recurrence. Apoptosis. 2014; 19: 1581-1593.

82. Shimazu T, Asada K, Charvat $H$, Kusano $C$, Otake $Y$, Kakugawa $Y$, et al. Association of gastric cancer risk factors with DNA methylation levels in gastric mucosa of healthy Japanese: $A$ cross-sectional study. Carcinogenesis. 2015; 36: 1291-1298.

83. White AJ, Sandler DP, Bolick SC, Xu Z, Taylor JA, DeRoo LA. Recreational and household physical activity at different time points and DNA global methylation. Eur J Cancer. 2013; 49: 2199-2206.

84. Herranz M, Martin-Caballero J, Fraga MF, Ruiz-Cabello J, Flores JM, Desco M, et al. The novel DNA methylation inhibitor zebularine is effective against the development of murine T-cell lymphoma. Blood. 2006; 107: 1174-1177. 
85. Huang, $\mathrm{MH}, \mathrm{Chou}, \mathrm{YW}, \mathrm{Li}, \mathrm{MH}$, et al. Epigenetic targeting DNMT1 of pancreatic ductal adenocarcinoma using interstitial control release biodegrading polymer reduced tumor growth through hedgehog pathway inhibition. Pharmacol Res. 2019; 139: 50-61.

86. Park H, Chung H, Lee J, Jang J, Kim Y, Kim SJ, et al. Decitabine as a first-line treatment for older adults newly diagnosed with acute myeloid leukemia. Yonsei Med J. 2017; 58: 35-42.

87. Baccarelli A, Bollati V. Epigenetics and environmental chemicals. Curr Opin Pediatr. 2009; 21: 243-251.

88. Bollati V, Baccarelli A. Environmental epigenetics. Heredity. 2010; 105: 105-112.

89. Ahrens TD, Timme S, Hoeppner J, Ostendorp J, Hembach S, Follo M, et al. Selective inhibition of esophageal cancer cells by combination of HDAC inhibitors and Azacytidine. Epigenetics. 2015; 10: 431-445.

90. Wang LT, Liuo JP, Li YH, Liu YM, Pan SL, Teng CM. A novel class 1 HDAC inhibitor, MPT0G030, induces cell apoptosis and differentiation in human colorectal cancer cells via HDAC1/PKC and E-cadherin. Oncotarget. 2014; 5: 5651-5662.

91. Apuri, S, Sokol, L. An overview of investigational histone deacetylase inhibitors (HDACls) for the treatment of Non-Hodgkin's lymphoma. Expert Opin Investig Drugs. 2016; 25: 687-696.

92. Mann BS, Johnson JR, Cohen MH, Justice R, Pazdur R. FDA approval summary: Vorinostat for treatment of advanced primary cutaneous T-cell lymphoma. Oncologist. 2007; 12: 1247-1252.

93. Coiffier B, Pro B, Prince HM, Foss F, Sokol L, Greenwood M, et al. Results from a pivotal, openlabel, phase II study of romidepsin in relapsed or refractory peripheral T-cell lymphoma after prior systemic therapy. J Clin Oncol. 2012; 30: 631-636.

94. Poole RM. Belinostat: First global approval. Drugs. 2014; 1543-1554.

95. Oki Y, Buglio D, Fanale M, Fayad L, Copeland A, Romaguera J, et al. Phase I study of panobinostat plus everolimus in patients with relapsed or refractory lymphoma. Clin Cancer Res. 2013; 19: 6882-6890.

96. Pillai R. MicroRNA functions: Multiple mechanisms for a tiny RNA. RNA J. 2005; 11: 1753-1761.

97. Bentwich I, Avniel A, Karov Y, Aharonov R, Gilad S, Barad O, et al. Identification of hundreds of conserved and nonconserved human microRNAs. Nat Genet. 2005; 37: 76670.

98. Shah PP, Hutchinson LE, Kakar SS. Emerging roles of miRNAs in diagnosis and treatment of various diseases including ovarian cancer. J Ovarian Res. 2009; 2: 11.

99. Rupaimoole R, Slack FJ. MicroRNA therapeutics: Towards a new era for the management of cancer and other diseases. Nat Rev Drug Discov. 2017; 16: 203-222.

100.Grossi I, Salvi A, Abeni E, Marchina E, De Petro G. Biological function of miR-193a-3p in health and disease. Int J Genomics. 2017; 2017: 5913195. doi: 10.1155/2017/5913195.

101. Mekala JR, Naushad SM, Ponnusamy L, Arivazhagan G, Sakhtiprasad V, Pal-Bhadra M.Epigenetic regulation of miR-200 as the potential strategy for the therapy against triplenegative breast cancer. Gene. 2018; 641: 248-258.

102.Demeure MJ, Armaghany T, Ejadi S, Ramanathan RK, Elfiky A,Strosberg JA, et al. A phase I/II study of TKM-080301, a PLK1-targeted RNAi in patients with adrenocortical cancer (ACC). J Clin Oncol. 2016; 34 (15 suppl): 2547.

103.Duenas-Gonzalez A, Coronel J, Cetina L, Cano C, Dolores R. Hydralazine-valproate: A repositioned drug combination for the epigenetic therapy of cancer. Expert Opin Drug Metab. 2014; 10: 1433-1444. 
104.Wu YS, Quan Y, Zhang DX, Liu DW, Zhang XZ. Synergistic inhibition of breast cancer cell growth by an epigenome-targeting drug and a tyrosine kinase inhibitor. Biol Pharm Bull. 2017; 40: 1747-1753.

105.Golan T, Khvalevsky EZ, Hubert A, Gabai RM, Hen N, Seqal A, et al. RNAi therapy targeting KRAS in combination with chemotherapy for locally advanced pancreatic cancer patients. Oncotarget. 2015; 6: 24569-24570.

106.Chiappinelli KB, Zahnow CA, Ahuja N, Baylin SB. Combining Epigenetic and Immunotherapy to Combat Cancer. Cancer Res. 2016; 76: 1683-1689.

107.Khan S, Shukla S, Sinha S, Meeran SM. Epigenetic targets in cancer and aging: Dietary and therapeutic interventions. Expert Opin Ther Targets. 2016; 20: 689-703.

108.Shukla S, Penta D, Mondal P, Meeran SM. Epigenetics of breast cancer: Clinical status of epidrugs and phytochemicals. Adv Exp Med Biol. 2019; 1152: 293-310.

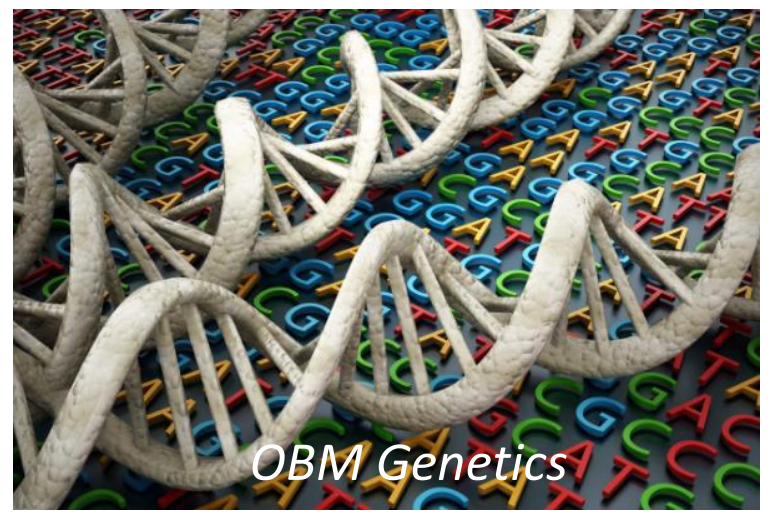

Enjoy OBM Genetics by:

1. Submitting a manuscript

2. Joining in volunteer reviewer bank

3. Joining Editorial Board

4. Guest editing a special issue

For more details, please visit:

http://www.lidsen.com/journals/genetics 